\title{
Elevated Plasmodium infection and multiple insecticide resistance in the principal malaria vectors Anopheles funestus and Anopheles gambiae in a forested locality close to the airport of Yaoundé, the Capital city of Cameroon
}

Nkemngo Francis Nongley ( $\nabla$ nkemngo.francis@gmail.com )

Centre for Research in Infectious Diseases

Jean Leon Mugenzi Mbugulize

Centre for Research in Infectious Diseases

Ebai Terence

Centre for Research in Infectious Diseases

Abdoulaye Niang

University of Glasgow Institute of Biodiversity Animal Health and Comparative Medicine

Murielle Wondji

Liverpool School of Tropical Medicine

Micareme Tchoupo

Centre for Research in Infectious Diseases

Daniel Nguiffo Nguete

Centre for Research in Infectious Diseases

Williams Tchapga

Centre for Research in Infectious Diseases

Helen Irving

Liverpool School of Tropical Medicine

Stephen M. Ghogomu

University of Buea

Cyrille Ndo

Centre for Research in Infectious Diseases

COMAL Consortium

Institute for Tropical Medicine, University of Tubingen

\section{Steffen Borrmann}

Institute for Tropical Medicine, University of Tubingen and German Center for Infection Research, Tubingen

Charles S. Wondji 


\section{Research}

Keywords: Malaria, Anopheles funestus, Anopheles gambiae, Plasmodium infection, Insecticide resistance, Vector control, Cameroon

Posted Date: February 12th, 2020

DOl: https://doi.org/10.21203/rs.2.23277/v1

License: (c) (1) This work is licensed under a Creative Commons Attribution 4.0 International License. Read Full License 


\section{Abstract}

\section{Background}

Reducing the burden of malaria requires better understanding of vector populations particularly in forested regions where the incidence remains elevated. Here, we characterized malaria vectors in a locality near the international airport of Yaoundé, the capital city of Cameroon, including species composition, abundance, Plasmodium infection rate; insecticide resistance profiles and underlying resistance mechanisms.

\section{Methods}

Blood-fed adult mosquitoes resting indoors were aspirated from houses in April 2019 at Elende, a village located $2 \mathrm{~km}$ from the Yaoundé-Nsimalen airport. Female mosquitoes were forced to lay eggs to generate F 1 adult progeny. WHO bioassays were performed to assess resistance profile to insecticides. The threshold of insecticide susceptibility was fixed above $98 \%$ mortality rate and mortality rates below $90 \%$ were considered indicative of confirmed insecticide resistance according to the WHO test procedures for insecticide resistance monitoring. Furthermore, the molecular basis of resistance and Plasmodium infection rates were investigated.

Results

Anopheles funestus s.s. was most abundant species in Elende (85\%) followed by Anopheles gambiae s.s. (15\%) with both having a similar sporozoite infection rate. Both species exhibited high levels of resistance to pyrethroids ( $<40 \%$ mortality). An. gambiae s.s. was also resistant to DDT ( $9.9 \%$ mortality) and bendiocarb ( $54 \%$ mortality) while susceptible to organophosphate. An. funestus s.s. was resistant to dieldrin ( $1 \%$ mortality), DDT ( $86 \%$ mortality) but susceptible to carbamates and organophosphates. The DDT/pyrethroid L119F-GSTe2 resistance allele (8\%) and G119S ace -1 resistance allele (15\%) were detected in An. funestus s.s. and An. gambiae s.s. respectively. Furthermore, the high pyrethroid/DDT resistances in An. gambiae s.s. corresponded with an increase frequency of $1014 \mathrm{~F} \mathrm{kdr}$ allele $(95 \%)$. The CYP6P9a P450 resistance allele was absent in the An. funestus s.s. population meanwhile transcriptional profiling of candidate cytochrome P450 genes reveals the over-expression of CYP6P5 , CYP6P9a and CYP6P9b.

\section{Conclusion}

The resistance to multiple insecticide classes observed in these vector populations alongside the high Plasmodium infection rate highlights the challenges that public health vector control programs encounter in sustaining the regular effectiveness of contemporary insecticide-based control interventions in forested areas. More particularly, the resistance observed against the carbamates and possible resistance against the organophosphates constitutes a major concern for IRS. 


\section{Background}

Malaria is the major vector-borne disease globally and a leading public health problem [1]. In 2018, there were roughly 228 million cases of the disease and about 405,000 malaria-related deaths. Approximately $70 \%$ and $20 \%$ of deaths recorded were children aged below five years and pregnant women respectively [1]. Although, a shift in focus from malaria control to elimination was declared by the WHO in 2012, it was observed that between 2015 and 2018; no considerable progress was achieved in decreasing global malaria cases. Rather, there was a reported increase in malaria cases in 2018 compared with the previous years in ten African countries scoring the highest burden of the disease [1].

To this effect, the WHO Global Technical Strategy for Malaria (2016-2030) outlines a pathway for malaria control and elimination and designates a target for a $90 \%$ reduction in global malaria mortality rates by 2030 relative to a 2015 baseline [2]. In this vein, the recent certification of Algeria and Argentina as malaria free countries by the World Health Organization (WHO) has been a historic achievement for universal health coverage, and serving as a model in demonstrating the feasibility of malaria elimination in the Afro-tropical region [1]. This success was in part largely attributed to a coordinated system of vector control interventions such as long-lasting insecticidal nets (LLINs) and indoor residual spraying (IRS) among others including prompt diagnosis, effective treatment and efficient surveillance response system [3]. Despite this, the efficacy of these insecticide based-vector control tools is compromised by the growing problem of insecticide resistance widely exhibited by Anopheles vectors across the African continent [4].

In Cameroon, malaria is endemic with the entire population considered to be at risk. Available data from health facilities reported $23.6 \%$ of cases, $68.7 \%$ of deaths among children aged less than 5 years and $16.9 \%$ of pregnancy related deaths attributed to malaria [5]. In order to reduce the malaria burden, the Cameroonian government supports the National Malaria Control Program (NMCP) and other partners who have established a strategic plan to achieve her goal of ensuring equal access to quality and affordable tools necessary for sustaining malaria control and elimination. The malaria interventions include mass distribution of long lasting insecticide nets (LLINs), prompt and effective diagnosis, artemisinin-based combination therapy (ACTs), seasonal malaria chemoprevention (SMC) and intermittent preventive therapy (IPT) in pregnant women through administration of sulfadoxinepyrimethamine [5]. Moreover, to further strengthen the current vector control intervention, an indoor residual spray (IRS) campaign is to be launched in Cameroon for the first time by the United States President Malaria Initiative (PMI) project. Unfortunately, the wide spread nature of insecticide resistance in malaria vectors to common insecticides used to impregnate nets and spray walls in Cameroon [6-10] threatens the success of this strategy.

In Cameroon, malaria is mainly transmitted by An. gambiae s.s, An. coluzzii, An. arabiensis, An. funestus s.s., An. nili and An. moucheti vectors [4] which have different geographical distributions across the country. However, despite such an important epidemiological role played by these vectors, data on the pattern of malaria transmission across different ecological settings in Cameroon including urban, semi- 
urban and rural remains insufficient [11]. This represents a major challenge for the realization of effective universal coverage of LLINs and universal access to anti-malaria drugs and treatment since malaria control requires a good understanding of the transmission dynamics. Currently, the absence of sufficient information on vector bionomics and disease transmission in rural areas could constitute a potentially steady malaria pool. This may serve as a bridge between rural and urban regions especially if high or residual transmission are maintained in such areas [12] thus posing a massive challenge for malaria control.

In order to facilitate and reinforce the National Malaria Control Program in their efforts to implementing sustainable and efficacious vector control interventions, this study investigated the situation of malaria transmission in a rural setting within the forested region of Cameroon. This included the characterization of the species composition, investigation of the insecticide resistance profiles of An. funestus s.s. and An. gambiae s.s. population collected in Elende in 2019, a forested village located $2 \mathrm{~km}$ away from the Nsimalen International Airport of Yaoundé, the capital city of Cameroon.

\section{Methods}

\section{Study area and mosquito collection}

Blood fed female mosquitoes were collected indoor in April 2019 from Elende $\left(3^{\circ} 41^{\prime} 57.27^{\prime \prime} \mathrm{N}, 11^{\circ} 33^{\prime} 28.46^{\prime}\right.$ 'E) (Fig.1), district of Nkolmefou I, a village close to Yaoundé; the capital city of Cameroon. This village is located about $2 \mathrm{~km}$ away from the Nsimalen International Airport and close to the Mefou River. This locality is categorized by an equatorial Guinean climate, represented by two rainy seasons (AugustOctober and March-May) and two dry seasons (November-February and June-July). The yearly average rainfall is $1800 \mathrm{~mm}$ while mean annual temperatures range between $19-28^{\circ} \mathrm{C}$, and the mean humidity varies between $65-80 \%$. The vegetation around the village is predominantly made up of an equatorial forest which is being degraded for farming activities and infrastructure. Road construction activities and deforestation are ongoing in this locality, an environmental modification system which creates temporal and permanent breeding sites for malaria vectors such as An. gambiae s.s. Moreover, the village is proximal to marshy lands and streams joining major rivers as these persistent water mass are ideal conditions; particularly favoring vector multiplication of An. funestus s.s. accompanied by an increase malaria transmission. Subsistence farming including cassava cultivation and vegetable cropping (particularly tomatoes, pepper, lettuce and watermelon) are the main human activities in this locality. The yield from this farming practices are greatly enhanced by the intensive use of pesticides. Also, household animals such as cattle, goats and sheep are present on a minor scale. Furthermore, several fish ponds bordered with vegetation exist in this village. This might encourage the development and growth of immature stages of the species within the An. funestus group. In this locality, pyrethroids containing LLINs is the main prevention method with a coverage of around 70\% [5] as the area is endemic for malaria. 
Following verbal approval from the chief and household heads; blood fed indoor resting adult mosquitoes (F0s) were collected between 06.00am and 11.00am. The Prokopack electrical aspirator (John W Hook, Gainesville, FL, USA) was used for mosquito collection after which they were kept in a humid cage and later transported to the insectarium of the Centre for Research in Infectious Diseases (CRID), Yaoundé. Field collected females were placed in a cage to rest for 1 hour prior to morphological identification [13]. Basically, each live mosquito sample was aspirated from the cage in to a hemolysis tube and observed microscopically for distinct morphological differences of wings, mouthparts and size based on the Afro-tropical anopheline key [13]. Specimens of the An. funestus group and An. gambiae complex were then placed in two separate small-sized labeled cages and allowed for 4-5 days feeding on $10 \%$ sugar soaked in cotton wool for them to become fully gravid. A forced-egg laying method as previously described $[14,15]$ was utilized for individual oviposition of females. After oviposition, all the carcasses of the $F_{0}$ were kept in separate $1.5 \mathrm{ml}$ tubes containing silica gel and stored at $-20^{\circ} \mathrm{C}$ prior to molecular analysis.

\section{Molecular species identification}

The Livak method was used to extract genomic DNA from a subset of each individually oviposited fieldcaught female $\left(\mathrm{F}_{0} \mathrm{~s}\right)$ [16]. DNA extracts were quantified using NanoDrop ${ }^{\mathrm{TM}}$ spectrophotometer (Thermo Scientific, Wilmington, USA). A SINE-200 PCR [17] and cocktail PCR [18] were performed to identify the different species within the An. gambiae s.l. complex and An. funestus s.l. group respectively. The ribosomal DNA internal transcribed spacer region 2 (ITS2) was amplified to identify the undetermined species using the protocol of Hackett et al [19]. The PCR amplicon of 840bp was purified with Exonuclease I (Exo I) and Shrimp Alkaline Phosphate method (Exo-SAP) based on the New England Biolabs procedure (NEB, MA, USA) and directly sequenced commercially.

\section{Plasmodium infection rates}

Plasmodium infection was assessed in 150 An. funestus s.s. and 39 An. gambiae s.s. F0 females. Genomic DNA was extracted from the head and thorax of each specimen, and infection with $P$. falciparum or OVM+ (P. ovale, $P$. vivax and $P$. malariae) was detected with the TaqMan assay as described previously [20]. Sequentially, nested PCR was conducted on all the positive samples to confirm the TaqMan assay results and to specifically differentiate between the OVM species obtained [21].

\section{WHO Insecticide susceptibility bioassays}

Various insecticides employed in control of malaria vectors were tested in bioassays to assess the resistance profile of the An. funestus s.s. and An. gambiae s.s. mosquito populations, according to the WHO protocol [22]. Brand new insecticide impregnated papers were supplied by WHO reference center (Vector Control Research Unit, University Sains Malaysia, Penang, Malaysia). Two- to five-day-old, unfed $\mathrm{F}_{1}$ female An. funestus s.s. were exposed for $1 \mathrm{~h}$ to discriminating concentrations of the following insecticides: pyrethroids [class I pyrethroids, permethrin (0.75\%), and the class II pyrethroid, deltamethrin $(0.05 \%)$ ]; the organochlorine [DDT (4\%) and dieldrin (4\%)]; the carbamates [bendiocarb $(0.1 \%)$ and 
propoxur (0.1\%)]; and the organophosphates; malathion (5\%). Similarly, An. gambiae s.s. female mosquitoes were exposed to all the insecticides except dieldrin and propoxur, instead fenithrothion (5\%) and primiphos-methyl (1.25\%) were added.

Furthermore, in order to establish the resistance intensity to pyrethroid insecticides, the An. gambiae s.s. $F_{1}$ generations from Elende were tested on permethrin and deltamethrin concentrations of $5 x$ and $10 x$ for 60 mins. Mortality rates were recorded $24 \mathrm{~h}$ post exposure. The dead mosquitoes were kept in $1.5 \mathrm{ml}$ tubes containing silica gel while the survivors were placed in tubes containing RNALater and stored at $-80^{\circ} \mathrm{C}$ for molecular analyses.

A set of 20-25 mosquitoes exposed to untreated papers were used as control for each test. The experiment was carried out at ambient temperatures of $25^{\circ} \mathrm{C} \pm 2{ }^{\circ} \mathrm{C}$ and $80 \% \pm 10 \%$ relative humidity. A mortality rate $>98 \%$ of the mosquito populations was considered susceptible to the insecticide, meanwhile suspected resistance was considered at mortality between $90-98 \%$, and resistant where mortality was found to be $<90 \%$.

\section{Piperonyl butoxide (PBO) synergist assay}

Only females of An. funestus s.s. were used for this assay since An. gambiae s.s. was inadequate in the study area at the period of collection. In order to determine the possible implication of cytochrome P450s in the observed phenotypic resistance to pyrethroids, two to five days old $\mathrm{F}_{1}$ female An. funestus s.s. were initially exposed to $4 \%$ PBO for $1 \mathrm{~h}$ proceeded by immediate second exposure to permethrin $(0.75 \%)$ and deltamethrin $(0.05 \%)$ for another $1 \mathrm{~h}$ interval. The mortality was determined $24 \mathrm{~h}$ post exposure and compared with mortality achieved for mosquitoes subjected to the pyrethroids only. Differences in mortality among the various groups were analyzed and recorded [22].

\section{Assessment of bed net efficacy using cone assay}

Due to the insufficiency of Anopheles gambiae s.s., in this locality, we examined the efficacy of bed nets approved by WHO against the Elende An. funestus s.s. population. This was done to evaluate the impact of resistance on insecticide targeted interventions against Anopheles vectors in this village. Basically, cone bioassays were performed according to the WHO procedure [23] using four standard types of LLINs (Olyset Plus, Olyset Net, PermaNet 2.0 and PermaNet 3.0 (side and roof)). Brand new PermaNet and OlysetNet nets manufactured in 2018 were supplied by the companies, Vestergaard, Lausanne, Switzerland and Sumitomo Chemical Plc, London, UK respectively. Four replicates of ten unfed mosquitoes were introduced into each plastic cone attached on pieces of fresh, unused bed nets of dimension $30 \mathrm{~cm} \times 30 \mathrm{~cm}$ : Olyset ${ }^{\circledR}$ Net (containing $2 \%$ permethrin), OlysetPlus ${ }^{\circledR} N$ et (containing $2 \%$ permethrin combined with $1 \%$ of the synergist PBO), PermaNet ${ }^{\circledR} 2.0$ (containing $1.4-1.8 \mathrm{~g} / \mathrm{kg} \pm 25 \%$ deltamethrin), and PermaNet ${ }^{\circledR} 3.0$ [both the side panel (containing $2.1-2.8 \mathrm{~g} / \mathrm{kg} \pm 25 \%$ deltamethrin) and the roof (containing $4.0 \mathrm{~g} / \mathrm{kg} \pm 25 \%$ deltamethrin, combined with $25 \mathrm{~g} / \mathrm{kg} \pm 25 \%$ of PBO)]. In a similar way, four replicates of ten mosquitoes each were included in each batch of the LLIN cone test and exposed to an untreated net to serve as negative control. For each test, 3 min was the exposure time. After exposure, 
the mosquitoes were gently and immediately removed from the cones using a mouth aspirator, transferred into paper cups and fed with $10 \%$ sucrose soaked in cotton wool. The number of mosquitoes knocked-down was recorded after $1 \mathrm{~h}$ while mortality was calculated after $24 \mathrm{~h}$ of observation. The experiment was carried out at ambient temperature of $25^{\circ} \mathrm{C} \pm 2{ }^{\circ} \mathrm{C}$ and $80 \% \pm 10 \%$ relative humidity.

\section{Genotyping of L119F-GSTe2, CYP6P9a, A296S-RDL, resistance marker in Anopheles funestus s.s}

An allele specific PCR was used to genotype and determine the frequency of the L119F-GSTe2 mutation in An. funestus s.s. $F_{0}$ mosquito population of Elende as previously described [24, 25]. This was to investigate the role of glutathione S-transferases in DDT resistance. The presence of CYP6P9a resistant allele associated with resistance to pyrethroids was genotyped by a PCR-RFLP assay [26] while the A296S-RDL mutation known to be linked with dieldrin resistance was also genotyped by TaqMan assay [27].

\section{Genotyping of L1014F, L1014S kdrand G119S ace-1 resistance marker in Anopheles gambiae s.s.}

The L1014F-kdr and L1014S-kdr mutations involved in pyrethroid and DDT resistance in An. gambiae s.s. were genotyped in $\mathrm{F}_{0}$ Elende mosquitoes using the TaqMan assay [28]. In addition, the G119S ace-1 responsible for carbamate and organophosphate resistance in An. gambiae s.s. was also genotyped in Elende mosquitoes using a TaqMan assay as previously described [29].

\section{Transcription profiling of candidate resistance associated genes}

A quantitative Reverse Transcriptase PCR (qRT-PCR) was done to investigate the prominent role of some previously reported Cytochrome P450 detoxification genes (CYP325A, CYP6P5, CYP6P9a and CYP6P9b) in An. funestus s.s. associated to the phenotypic resistance recorded during bioassay [30-32]. Using a triplicate of $10 \mathrm{~F}_{1}$ females each that recovered after $1 \mathrm{~h}$ exposure to permethrin from Elende and 3 batches of unexposed $10 \mathrm{~F}_{1}$ females that were used as control samples; total RNA extraction, cDNA synthesis and qRT-PCR reactions were performed as earlier reported [30]. Fold change and expression of each gene in resistant $(R)$ and control $(C)$ samples were computed according to 2- $\Delta \Delta C T$ method [33] following standardization with housekeeping genes RSP7 ribosomal protein S7 (AFUN007153-RA) and the Actin 5C (AFUN006819) gene.

\section{Results}

\section{Species identification}

A total of 269 adult resting female Anopheles mosquitoes were collected indoor at Elende over a two-day period. Out of the total sample collected; 230 (85.50\%) were members of An. funestus group while the remaining $39(14.49 \%)$ species belonged to the An. gambiae complex.

From the 120 An. funestus s.I. mosquitoes that were chosen randomly and identified using cocktail PCR, An. funestus s.s. was dominant [98.34\% (118/120)] with An. rivolurum [0.83\% (01/120)] and An. 
vaneedeni [0.83\% (01/120)] also detected. Similarly, from the 39 An. gambiae s.I. mosquitoes collected and analyzed using SINE PCR, all were An. gambiae s.s. Furthermore, the results of ITS-2 sequencing confirmed the undetermined mosquitoes from cocktail PCR to be An. funestus s.s. Out of the 230 and 39 mosquitoes morphologically identified, 196 (85.22\%) An. funestus s.s. and 20 (51.28\%) An. gambiae s.s. laid eggs respectively by the forced egg laying technique.

\section{Plasmodium infection rate}

The analysis of the head and thorax revealed 10/150 (6.66\%, Cl: 4.46-8.86) infected An. funestus s.s. mosquitoes, which included 08 (5.33\%, Cl: 2.67-7.33) P. falciparum and 02 (1.33\%, Cl: 0.66-2.97) mosquitoes infected with either $P$. ovale, $P$. vivax or $P$. malariae (OVM). The Plasmodium infected mosquitoes revealed by TaqMan was further confirmed with nested PCR. Results of nested PCR reported $05 P$. falciparum positive samples and 02 samples infected with $P$. malariae.

Out of 39 collected An. gambiae s.s., 5.13\% [(02/39) (Cl: 2.57-7.13)] were infected with P. falciparum and none for $P$. OVM or mixed infections. Nested PCR confirmed 01 positive $P$. falciparum sample out of the 02 infected samples detected by TaqMan assay.

\section{Insecticide susceptibility assays}

A sum of $598 \mathrm{~F}_{1}$ female An. funestus s.s. mosquitoes were tested to determine the resistance profile to seven insecticides (Fig. 2). An. funestus s.s. was resistant to class I and class II pyrethroids. Mortality to permethrin (type I pyrethroid) was $37.00 \pm 6.59 \%$ while for deltamethrin (type II pyrethroid), mortality was $29.80 \pm 0.86 \%$ (Fig. 2a). Regarding the organochlorine insecticides, moderate resistance to DDT was recorded with a mortality rate of $86.25 \pm 8.98 \%$ (Fig. 2a). However, extremely high resistance was noticed for dieldrin with a recorded mortality value of $1.04 \pm 1.04 \%$ (Fig. 2a). For the carbamates, full susceptibility was observed for propoxur with a mortality rate of $100 \%$ whereas a near susceptibility was noted for bendiocarb with a mortality value of $97.22 \pm 2.77 \%$ (Fig. 2a). A full susceptibility was obtained for the organophosphate, malathion with $100 \%$ mortality (Fig. 2a).

The An. gambiae s.s. population was highly resistant to class I and class II pyrethroids. Mortality to permethrin was $5.00 \pm 0.06 \%$ and $11.32 \pm 1.40 \%$ for deltamethrin (Fig. $2 b$ ). Due to the high resistance observed for the diagnostic concentration of pyrethroids, an increased concentration of permethrin ( $5 \mathrm{x}$ and 10x) and deltamethrin ( $5 x$ and 10x) was used to further determine the extent of resistance intensity on the $\mathrm{F}_{1}$ An. gambiae s.s. population. Resistance to $5 \mathrm{x}$ and $10 \mathrm{x}$ permethrin was observed with a recorded mortality rate of $31.82 \%$ and $44.00 \%$ respectively. In a similar manner, mortality rate upon exposure to $5 x$ and $10 x$ deltamethrin was observed at $20.00 \%$ and $28.57 \%$ respectively (Fig. 2b). Regarding the organochloride insecticide DDT, an elevated resistance pattern was observed with a mortality rate of $9.98 \pm 1.03 \%$ (Fig. 2b). Resistance to the carbamate insecticide, bendiocarb was recorded with a mortality value of $54.56 \pm 1.05 \%$ (Fig. $2 \mathrm{~b}$ ). Moreover, for the organophosphate insecticides, mortality rates of $95.24 \pm 1.94 \%, 95.23 \pm 0.09 \%$, and $96.75 \pm 1.63 \%$ were observed for malathion, fenithrothion and 
pirimiphos-methyl respectively (Fig. 2b) suggesting possible resistance that necessitates further confirmation.

\section{PBO synergist assays with An. funestus s.s.}

Initial exposure of $169 \mathrm{~F} 1$ An. funestus s.s. mosquitoes to PBO led to return of susceptibility to both class I and II pyrethroids with full mortality recorded after PBO + pyrethroid exposure from $51.50 \pm 7.19 \%$ to $100 \%$ for permethrin and from $19.22 \pm 10.76 \%$ to $100 \%$ mortality for deltamethrin (Fig. 3a).

\section{Assessment of bed net efficacy on An. funestus s.s. population by cone assays}

Out of the $192 \mathrm{~F} 1$ An. funestus s.s. used to assess the efficacy of conventional bed nets, a reduced efficacy was seen for both pyrethroid-only impregnated nets with low mortality rate observed for Olyset net $(24.97 \pm 6.45 \%)$ and PermaNet $2.0(7.27 \pm 4.75 \%) 24 \mathrm{~h}$ after mosquito exposure (Fig. 3b). In opposite, nets impregnated with PBO exhibited a significantly greater efficacy with full susceptibility for both PermaNet 3.0 top (100\% mortality) and Olyset plus (100\% mortality). However, a lower efficacy was recorded for the side part of PermaNet 3.0 (19.17 $\pm 5.46 \%$ mortality). The susceptible strain for $A n$. funestus FANG, used as control demonstrated full mortality to all nets (Fig. 3b).

\section{Genotyping of L119F-GSTe2, Cyp6P9a and A296S-RDL resistance markers in An. funestus s.s}

A subset of $50 \mathrm{~F}_{0}$ females collected from the field was used for genotyping L119F-GSTe2 molecular marker (Fig. 4a). Out of this cohort, 04 mosquito samples were homozygous resistant (RR) (8\%), 40 were heterozygous (RS) (80\%) and 06 were homozygous susceptible (SS) (12\%). Overall, the frequency of the $119 \mathrm{~F}$ resistant allele (R) was $48 \%$ and $52 \%$ for the $\mathrm{L} 119$ susceptible allele (S).

The PCR-RFLP genotyping of CYP6P9a revealed that all the mosquitoes were homozygous susceptible with a band size of about 500bp (Fig. 4a) indicating that this mutation is absent in An. funestus s.s. population of Elende.

Also, the 50 samples genotyped for A296S marker were all homozygous resistant RR (100\%), revealing that the mutation is fixed in this population (Fig. 4a) in line with the high dieldrin resistance observed.

\section{Genotyping of L1014F, L1014S kdr and G119S ace-1 markers in An. gambiaes.s}

Out of 39 samples genotyped for L1014F kdr resistance marker, 36 were homozygous resistant RR (92.30\%), 02 were heterozygous RS (5.13\%) and 01 homozygous susceptible SS (2.56\%) with a 1014F resistant allele frequency of $94.86 \%$ (Fig. 4b). Likewise, out of the 39 samples genotyped for the L1014S marker, 01 was RS (2.56\%) and 38 were SS (97.43\%) (Fig. 4b). Thus, a very low frequency of $1.28 \%$ was observed for the1014S resistant allele.

Similarly, out of 39 samples genotyped for the G119S resistance marker, 06 were homozygous resistant RR (15.38\%), 01 was heterozygous resistant RS (2.56\%) and 32 were found to be homozygous 
susceptible SS (82.05\%) (Fig.4b). Overall, the frequency of the $119 \mathrm{~S}$ resistant allele was $16.66 \%$.

\section{Transcriptional profiling of candidate genes}

A quantitative Reverse Transcriptase PCR (qRT-PCR) was done to examine the role of some previously reported Cytochrome P450 metabolic genes in An. funestus s.s. linked to the resistance observed during bioassay. The qRT-PCR results reveal that CYP6P5, CYP6P9a and CYP6P9b genes known to be involved in pyrethroid resistance are significantly up-regulated in An. funestus s.s. population from Elende as compared to the susceptible laboratory strain FANG (Fig. 5). Both CYP6P9a and CYP6P9b exhibited a 6 fold change in Elende resistant mosquito when compared to FANG $(P<0.05)$ whereas CYP6P5 displayed a 2.20 fold change difference in expression $(P<0.05)$ between the wild mosquitoes and susceptible strain. On the other hand, when comparing permethrin exposed to the unexposed (control) mosquito and FANG strain, CYP325A was not significantly expressed.

\section{Discussion}

Rapid scaling up of vector control interventions is ongoing in Cameroon, where malaria is highly endemic. As such, characterization of local vectors alongside investigation of their resistance profile is essential for the effective designing and execution of successful and sustainable vector control interventions as well as for evaluating the impact of insecticides resistance. In the past, the possibility of generating a large number of F1 progeny from small numbers of field collected mosquito for molecular characterization constituted a major hindrance for colonizing An. funestus in the lab. However, this limitation has been resolved by the invention of the forced-egg laying method [14]. An easy approach to addressing this barrier is by collecting indoor resting blood fed female mosquitoes and putting each of them in a confined $1.5 \mathrm{ml}$ tube to forcefully lay eggs. This method has made feasible the substantial evaluation of the susceptibility profile of this mosquito species population against different classes of insecticide. Nevertheless, for experiments involving F1 adults to be informative, it is cardinal that, the offsprings obtained by this technique should not be bias and family isolation effects must be reduced such that the progeny are typical of the overall population. In this regard, pooled egg batches were reared together and the F1 adults were randomly combined in cages for the various assays.

With the possibility of generating a large number of progeny from field collected female An. funestus and An. gambiae mosquitoes, this study therefore characterized the principal malaria vectors in a rural setting within the forested region of Cameroon; located $2 \mathrm{~km}$ away from the Yaoundé -Nsimalen International airport.

\section{Mosquito Species composition in Elende}

From the 09 species of An. funestus s.I. group described, An. funestus s.s., An. rivulorum and $A n$. vaneedeni were detected in Elende, with abundance of $98.34 \%, 0.83 \%$ and $0.83 \%$ respectively. This result is similar to a study conducted in Tibati [34] and Gounougou (northern region of Cameroon), where An. funestus s.s. accounted for $99.50 \%$ of the species collected and Anopheles leesoni was 0.50\% [9]. 
Likewise, the result reflects the species abundance in a published study conducted in Mibellon (Cameroon) where An. funestus s.s. was the only dominant vector found within the group [11]. The superiority of An. funestus s.s. was also reported in Kpome-Benin (West Africa) [35]. Since this study was done at a single point in time, we cannot exclude the presence of other Anopheline species. More so, the study may have limited the collection of outdoor resting members of the group since mosquito sampling was concentrated indoors. However, this differs with the distribution of members of this group observed in eastern and southern regions of Africa where several member species were collected indoors. For example, An. parensis, An. leesoni and An. rivulorum were found in higher densities indoors in a study in Uganda and southern Africa [36-40].

The dominance of An. funestus s.s. within the An. funestus group in this locality further confirms the extremely anthropophilic and endophilic nature of this species which is highly involved in the transmission of human malaria. This result supports the broad geographical distribution of An. funestus s.s. in Cameroon where it stands as a major malaria vector [11]. Nonetheless, further studies are required to determine the blood meal source of the major Anopheles vectors and their species abundance in outdoor settings in order to have an overview of the vectorial capacity and malaria transmission dynamics in this locality.

Regarding the An. gambiae complex, An. gambiae was the only species found. This result is similar to previous studies demonstrating that An. gambiae s.s. was the major species in rural and semi-rural areas of the Centre and Littoral regions in Cameroon, particularly in Yaounde and Douala [41-43].

\section{Roles of both vectors in malaria transmission in forested areas}

This study confirms the role of An. funestus s.s. and An. gambiae s.s. in malaria transmission in this locality with sporozoite infection rate of $6.66 \%$ and $5 \%$ respectively. This result is similar to $A n$. funestus s.s. sporozoite infectivity rate in Mibellon (5\%) but higher than in Obout (3.2\%) and Tibati (2.94\%). In Benin (Kpome), whole mosquito extracted DNA of An. funestus s.s. population found high Plasmodium infection during the dry season (18.20\% infection rate) [35].

Due to the low number of the field collected An. gambiae s.s. during the study period, infection with Plasmodium (5\%) was lower compared to An. funestus s.s. (6.6\%). Also, this rate is similar to previous results in Cameroon [10]. Because the location of Elende is close to the Nsimalen-International Airport and to the city of Yaoundé, efforts should be made to reduce the malaria transmission in this locality to avoid it constitute a reservoir for transmission in the city particularly as it was recently shown that mosquitoes can fly over long distances [12].

\section{Multiple and high insecticide resistance in both major vectors constitutes a challenge for vector control in forested areas.}

Insecticide resistance profile of An. funestus s.s. in Elende locality is similar to previous studies in Cameroon documented for this species where resistance against all pyrethroids and full susceptibility 
to organophosphates was observed [11]. The multiple insecticide resistance patterns observed in the An. funestus s.s. population to pyrethroids and DDT in Elende corresponds to the trends observed in Gounougou (2012) [9] and higher than in Obout (2016) [44] but lower than in Tibati (2018) [34]. Moreover, the high resistance pattern of An. funestus s.s. to pyrethroids observed in this locality is similar to that observed in Mibellon (2017) [11]. This result brings to attention the fact that resistance in An. funestus s.s. is pervasive in Cameroon and constitute a threat for operational insecticide-based vector control tools directed at this species. In Cameroon, the massive deployment of LLINs implemented by the Cameroonian Government in the past years has likely contributed to a rapid rise of pyrethroid resistance in An. funestus s.s. vector. Moreover, Elende is also located in an area where farming is widely practiced, and agricultural application of pesticides for crop protection apparently imposes a selective pressure that further pilots the increase in resistance level. Similarly, this same pattern of high pyrethroid resistance in An. funestus s.s. was observed in southern Africa in Malawi [45], Mozambique [46]; East African region including Uganda [47]; and West Africa in Ghana [48], Benin [35] and Nigeria [49].

The full reversal to susceptibility observed after PBO exposure to permethrin and deltamethrin, implies that cytochrome P450 genes are playing a notable role in the resistance mechanisms. This increasingly higher resistance to pyrethroids poses a remarkable challenge for malaria control programs in Cameroon and necessitates the urgent implementation of insecticide resistance management strategies so as to prevent failure of future programs directed at scaling-up distribution campaigns of pyrethroid impregnated LLINs.

Extremely high levels of resistance to several classes of insecticides, including organochlorine, pyrethroid and carbamate, were also noticed in An. gambiae s.s. population from Elende. Moreover, the intense resistance of An. gambiae s.s. to $5 \mathrm{x}$ and $10 \mathrm{x}$ concentration of permethrin and deltamethrin each suggests that the resistance is elevated in this population. This elevated resistance in An. gambiae s.s. corresponds with the high level of resistance reported in this species across various sites in Cameroon [6$8,34]$. Furthermore, the reduced susceptibility observed against the organophosphates (malathion, fenithrothion and pirimiphos-methyl) in An. gambiae s.s. is an indication of possible cross resistance with the carbamates since both insecticides class act on the same nervous system target site. In this regards, carbamates insecticide should be excluded as a replacement to pyrethroid for IRS as this will further select the spread of the resistant allele within the species population of this locality.

The resistance in An. gambiae s.s. was higher compared to An. funestus s.s. for almost all the insecticides during this time interval, suggesting a substantial selection pressure acting on An. gambiae s.s. This could be as a result of environmental and genetic selection of resistance from breeding sites polluted with pesticides used for crop protection. Since An. gambiae s.s. temporal breeding sites are often located nearby areas of crop cultivation, the selection would be enormous in this species compared to $A n$. funestus s.s.

\section{Bio-efficacy of LLINs in cone assays}


Freely distributed LLINs by the National Malaria Contol Programme (NMCP) constitute the central malaria vector control intervention in Elende. The dramatic drop in potency of these solely impregnated pyrethroid nets is comparable to cases reported in other localities in Cameroon [11] and Africa $[35,46]$. Resistance to pyrethroids in this species is linked with a tremendous decline in efficacy to all pyrethroid only LLINs as demonstrated by the diminishing mortality rates against PermaNet 2.0 $(<10 \%)$ and Olyset net (<25\%). In opposite, PBO-based nets demonstrated a greater efficacy with the highest reported by both PermaNet 3.0 top and Olyset plus scoring $100 \%$ mortality. This indicates that cytochrome $\mathrm{P} 450$ genes are probably propelling pyrethroid resistance in this locality. The higher mortality rate observed with PBO-based nets suggest that these synergist nets including Olyset Plus and PermaNet 3.0 (roof) should be regarded as a substitution to pyrethroid-only nets in areas of increasing resistance fueled by metabolic mechanisms particularly for cytochrome P450s as it is the situation for An. funestus s.s. [29].

\section{Elevated metabolic resistance in $A n$. funestus differs with high levels of knockdown resistance in $A n$. gambiae}

The full susceptibility noticed for pyrethroids in An. funestus s.s. after first-exposure to PBO points out that metabolic resistance mediated by cytochrome P450s is the main mechanism [50]. This is linked to previous studies which confirm the absence of $k d r$ target site sensitivity mutation in this species in Cameroon [9] and across Africa [51]. In the absence of voltage-gated sodium channel knockdown resistance mutations in An. funestus s.s. [51], this study demonstated that pyrethroid resistance in Elende populations of An. funestus s.s. is possibly steered by metabolic resistance machinery. Overall, the role of metabolic resistance is apparent by the marked up-regulation of the three P450 genes (CYP6P5, CYP6P9a, and CYP6P9b) already reported as essential genes conferring pyrethroid resistance in $A n$. funestus s.s. populations across Africa [30].

The absence of the CYP6P9a resistant allele in An. funestus s.s. population from Elende corresponds to the study by Weedall et al [26]. This confirms the fact that this mutation, fixed in mosquitoes from southern Africa is not yet present in mosquitoes from Central/West Africa [26].

Cross-resistance between DDT and pyrethroids has been demonstrated to be conferred by GSTe2. In relation to this, the frequency of the L119F-GSTe2-resistant allele in Elende field population $(48 \%)$ is higher than in Mibellon (28\%), Tibati (10.2\%) and lower than in Gounougou (52\%). Similarly, across Africa, the frequency of the DDT resistance marker was closer to that observed in Democratic Republic of Congo [52] and Ghana [48]; higher than the frequency reported in eastern part of Africa, Uganda [36, 37] although lower to studies in Benin [35].

The frequency of the 296S-RDL-resistant allele is $100 \%$ which is higher as compared in the northern region; particularly in Mibellon (9.7\%), Gounougou (14.6\%) and Tibati (0.4\%). However, this result is similar to mortality rate recorded in An. funestus s.s. from Obout that exhibited very high level of resistance to dieldrin (4.35\% mortality rate) [44]. This high frequency could be as a result of strong 
resistance selection due to environmental persistence of insecticide residues since its withdrawal from public and agricultural use in Cameroon.

The elevated resistance levels to pyrethroids in An. gambiae s.s. accords with the increased frequency of the $1014 \mathrm{~F} k d r$ allele (94.9\%). This correlates with past studies done in Africa where high pyrethroid resistance in An. gambiae s.I. has been coupled with almost fixed $k d r$ allele in the population, as recently reported in DR Congo [52], or earlier in Côte d'Ivoire [53]. Consistent with previous research performed in other parts of Cameroon [8, 34], this study found elevated frequencies of the $k d r$ mutation in An. gambiae s.s. population in Elende that has almost reached fixation.

The very low frequency of the $1014 S$ sdrallele in Elende $(1.28 \%)$ is in parallel to earlier reports across Cameroon exhibiting that this target site resistance mutation, originally discovered in East Africa, is gradually spreading to Central and West Africa although still at very low occurrence [54].

The presence of the 119S ace 1 mutation in An. gambiae s.s. population is in line with the reduced susceptibility observed in this population to carbamates and organophosphates [55-57]. The use of carbamates and organophosphates may be regarded as an alternative for the management of this highly insecticide resistant vector population although the detection of Ace 1 is also a cause of concern.

Overall, similar studies should be conducted across different ecological settings in Cameroon to establish the epidemiological and entomological parameters of malaria transmission and investigate the resistance profile of malaria vectors to existing insecticides. Specifically, a longitudinal survey would obviously provide useful and interesting information on the seasonal species composition and abundance, in-depth knowledge on the biology of each species, mosquito host-seeking and resting preferences, pattern of insecticide resistance, frequency of insecticide resistance genes and the role played by Anopheles vectors in malaria transmission in this locality over time. Data produced from such future studies will be relevant in generating additional significant information required to strengthen malaria control.

\section{Conclusion}

This study reports the characterization and resistance profile of the major malaria vectors An. funestus and An. gambiae in Elende locality, situated close to a port of entry in Yaounde, the capital city of Cameroon. The high Plasmodium infection rate alongside the resistance to multiple insecticide classes observed in these vector populations highlights the challenges that public health vector control programs encounter in sustaining the regular effectiveness of contemporary insecticide-based control interventions aimed at reducing malaria transmission in forested areas. More particularly, the resistance observed against the carbamates and possible resistance against the organophosphates constitutes a major concern for IRS; while suggesting the susceptibility testing of Anopheles malaria vectors in this locality to neonicotinoids and pyrrole insecticides in preparation for indoor residual spraying campaigns with novel insecticide ingredients. Also, this study further provides operational evidence to National Malaria Control 
Programs for a shift from mass distribution of pyrethroid-only LLINs to second-generation bed nets (containing synergist) in areas where high resistance is driven by metabolic mechanisms notably cytochrome P450s.

\section{Abbreviations}

DDT: dichlorodiethyltrichloroethane; DNA: deoxyribonucleic acid; dNTPs: deoxyribonucleoside triphosphates; GSTe2: glutathione S-transferase epsilon 2; IRS: indoor residual spraying; kdr: knockdown resistance mutation; LLIN: long-lasting; insecticidal net; NMCP: National Malaria Control Programme; PBO: piperonyl butoxide; PCR: polymerase chain reaction; s.l.: sensu lato; s.s.: sensu stricto; WHO: World Health Organization.

\section{Declarations}

\section{Authors' contributions}

CSW conceived, designed and coordinated the research. CSW, NNF, ET, WT and AN carried out the sample collection and mosquito rearing. NNF and LMJM conducted the bioassays. NNF, LMJM, NDN, MW and MT performed the PCR and TaqMan assays. HI and MW performed the ITS-2 sequencing. NNF, LMJM and CSW contributed toward data analysis. NNF, LMJM, COMAL Consortium, SMG, CN, SB and CSW wrote the manuscript with contribution from all the authors. All authors read and approved the final manuscript.

\section{Acknowledgements}

We thank the inhabitants of the Elende community for their support during the sample collection and Yvan Fotso for assisting with the map of Elende. The following are members of the COMAL consortium: Ayola Akim Adegnika, Centre de Recherches Médicales de Lambaréné, Lambaréné, Gabon, Eberhard Karls Universität Tübingen, Tübingen, Germany, Institute for Tropical Medicine, University of Tübingen, Germany \& German Center for Infection Research (DZIF), Tübingen, Germany; Francine Ntoumi, Institute of Tropical Medicine, University of Tübingen, Germany, Fondation Congolaise pour la Recherche Medicale (FCRM), Brazzaville, République du Congo and Université Marien Ngouabi, Brazzaville, République du Congo; Luc Djogbenou, Institut Régional de Santé Publique /Université d'Abomey-Calavi, République du Benin, Saadou Issifou, Eberhard Karls Universität Tübingen, Tübingen, Germany; Romaric Akoton, Institut Régional de Santé Publique /Université d'Abomey-Calavi, République du Benin ; Felix Koukouikila, Fondation Congolaise pour la Recherche Medicale (FCRM), Brazzaville, République du Congo and Université Marien Ngouabi, Brazzaville, République du Congo; Tatiana Rockl-Pinilla, Institute of Tropical Medicine, University of Tübingen, Germany and Centre des Recherches Médicales de Lambaréné Lambaréné, Gabon ; Stravensky Terence Boussougou-Sambe, Institute of Tropical Medicine, University of Tübingen, Germany and Centre des Recherches Médicales de Lambaréné Lambaréné, Gabon ; Romuald Agonhossou, Institut Régional de Santé Publique /Université d'Abomey-Calavi, République du Benin and 
Jacques Dollon Ntabi, Fondation Congolaise pour la Recherche Medicale (FCRM), Brazzaville, République du Congo and Université Marien Ngouabi, Brazzaville, République du Congo.

\section{Competing interests}

The authors declare absence of competing interests

\section{Consent for publication}

Not applicable.

\section{Ethics approval and consent to participate}

Not applicable.

\section{Availability of data and materials}

All the data generated by this study are included in the manuscript.

\section{Funding}

This work was funded by a Wellcome Trust Senior Research Fellowship in Biomedical Sciences to CSW (101893/Z/13/Z) and a DFG grant (BO 2494/3-1) to SB and CSW.

\section{References}

1. WHO: Malaria Report 2019. Geneva, Switzerland: World Health Organization; 2019

2. WHO: Malaria Report 2017. Geneva, Switzerland: World Health Organization; 2017

3. Bhatt S, Weiss D, Cameron E, Bisanzio D, Mappin B, Dalrymple U, et al. The effect of malaria control on Plasmodium falciparum in Africa between 2000 and 2015. Nature. 2015;526:207-11.

4. Hemingway J, Ranson H, Magill A, Kolaczinski J, Fornadel C, Gimnig J, et al. Averting a malaria disaster: will insecticide resistance derail malaria control? Lancet. 2016;387:1785-8.

5. PNLP. Rapport d'activites du programme National de Lutte contre le Paludisme. 2018 (unpublished data) ; https ://www.annua ire-medical.cm/ministere-sante publique/programmes -nationaux-sante /66-programme-national-lutte -contre-paludisme. Accessed 13 July 2019.

6. Antonio-Nkondjio C, Sonhafouo-Chiana N, Ngadjeu CS, Doumbe-Belisse P, Talipouo A, DjamoukoDjonkam $L$, et al. Review of the evolution of insecticide resistance in main malaria vectors in Cameroon from 1990 to 2017. Parasit Vectors. 2017;10:472.

7. Etang J, Manga L, Chandre F, Guillet P, Fondjo E, Mimpfoundi R, et al. Insecticide susceptibility status of Anopheles gambiae s.I. (Diptera: Culicidae) in the Republic of Cameroon. J Med Entomol. 2003;40:491-7 
8. Nwane P, Etang J, Chouaïbou M, Toto JC, Koffi A, Mimpfoundi R, et al. Multiple insecticide resistance mechanisms in Anopheles gambiae s.l. populations from Cameroon, Central Africa. Parasit Vectors. 2013;6:41

9. Menze BD, Riveron JM, Ibrahim SS, Irving H, Antonio-Nkondjio C, Awono- Ambene PH, et al. Multiple insecticide resistance in the malaria vector Anopheles funestus from Northern Cameroon is mediated by metabolic resistance alongside potential target site insensitivity mutations. PLoS ONE. 2016;11:e0163261

10. Fadel, A. N. Sulaiman SI, Tchouakui M. et al. A combination of metabolic resistance and high frequency of the $1014 \mathrm{~F} \mathrm{kdr}$ mutation is driving pyrethroid resistance in Anopheles coluzzii population from Guinea savanna of Cameroon. Parasit. Vectors (2019). doi:10.1186/s13071-019-3523-7

11. Menze, B. D. Murielle JW, Williams T. et al. (2018) 'Bionomics and insecticides resistance profiling of malaria vectors at a selected site for experimental hut trials in central Cameroon', Malaria Journal. BioMed Central, (February). doi: 10.1186/s12936-018-2467-2.

12. Huestis DL, Dao A, Diallo M, Sanogo ZL, Samake D, Yaro AS, Ousman Y, Linton YM, Krishna A, Veru L, Krajacich BJ, Faiman R, Florio J, Chapman JW, Reynolds DR, Weetman D, Mitchell R, Donnelly MJ, Talamas E, Chamorro L, Strobach E, Lehmann T. Windborne long-distance migration of malaria mosquitoes in the Sahel. Nature. 2019.

13. Gillies M, Coetzee M. A supplement to the Anophelinae of Africa south of the Sahara (Afrotropical region). Publ South Afr Inst Med Res. 1987;55:1-143.

14. Morgan JC, Irving H, Okedi LM, Steven A, Wondji CS. Pyrethroid resistance in an Anopheles funestus population from Uganda. PLoS ONE. 2010;5:e11872.

15. Cuamba N, Morgan JC, Irving H, Steven A, Wondji CS. High level of pyrethroid resistance in an Anopheles funestus population of the Chokwe District in Mozambique. PLoS ONE. 2010;5:e11010

16. Livak KJ. Organization and mapping of a sequence on the Drosophila melanogaster $X$ and $Y$ chromosomes that is transcribed during spermato- genesis. Genetics. 1984;107:611-34.

17. Santolamazza F, Mancini E, Simard F, Qi Y, Tu Z, Torre A. Insertion poly- morphisms of SINE200 retrotransposons within speciation islands of Anopheles gambiae molecular forms. Malar $\mathrm{J}$. 2008;7:163.

18. Koekemoer LL, Kamau L, Hunt RH, Coetzee M. A cocktail polymerase chain reaction assay to identify members of the Anopheles funestus (Dip- tera: Culicidae) group. Am J Trop Med Hyg. 2002;66:80411

19. Hackett, B. J. Gimnig J, Guelbeogo W, Costantini C. et al. Ribosomal DNA internal transcribed spacer ( ITS2 ) sequences differentiate Anopheles funestus and An . rivulorum, and uncover a cryptic taxon. 9, 369-374 (2000).

20. Bass C, Nikou D, Blagborough AM, Vontas J, Sinden RE, Williamson MS, et al. PCR-based detection of Plasmodium in Anopheles mosquitoes: a comparison of a new high-throughput assay with existing methods. Malar J. 2008;7:177. 
21. Snounou G, Viriyakosol S, Zhu XP, Jarra W, Pinheiro L, do Rosario VE,et al. High sensitivity of detection of human malaria parasites by the use of nested polymerase chain reaction. Mol Biochem Parasitol. 1993;61:315-20.

22. WHO: Test procedures for insecticide resistance monitoring in malaria vector mosquitoes, second edition. 2018.

23. WHO: Guidelines for laboratory and field testing of long-lasting insecticidal nets (2013)

24. Riveron JM, Yunta C, Ibrahim SS, Djouaka R, Irving H, Menze BD, et al. A single mutation in the GSTe2 gene allows tracking of metabolically based insecticide resistance in a major malaria vector. Genome Biol. 2014;15:R27

25. Tchouakui M, Riveron JM, Djonabaye D, Tchapga W, Irving H, Soh Takam P, et al. Fitness Costs of the Glutathione S-Transferase Epsilon 2 (L119F-GSTe2) Mediated Metabolic Resistance to Insecticides in the Major African Malaria Vector Anopheles funestus. Genes (Basel). 2018; 9(12).

26. Weedall, G. D. Mugenzi JL, Menze BD, Tchouakui M, Sulaiman SI. et al. A cytochrome P450 allele confers pyrethroid resistance on a major African malaria vector, reducing insecticide-treated bednet efficacy. 7386, (2019).

27. Wondji CS, Dabire RK, Tukur Z, Irving H, Djouaka R, Morgan JC. Identification and distribution of a GABA receptor mutation conferring dieldrin resistance in the malaria vector Anopheles funestus in Africa. Insect Biochem Mol Biol. 2011;41:484-91.

28. Bass C, Nikou D, Donnelly MJ, Williamson MS, Ranson H, Ball A, et al. Detection of knockdown resistance ( $k d r)$ mutations in Anopheles gambiae: a comparison of two new high-throughput assays with existing methods. Malar J. 2007;6:111

29. Weill, M., et al. Comparative genomics: insecticide resistance in mosquito vectors. Nature 423 (2003).

30. Riveron JM, Irving H, Ndula M, et al. Directionally selected cytochrome P450 alleles are driving the spread of pyrethroid resistance in the major malaria vector Anopheles funestus. Proc Natl Acad Sci U S A 2013; 110:252-7.

31. Riveron JM, Ibrahim SS, Chanda E, et al. The highly polymorphic CYP6M7 cytochrome P450 gene partners with the directionally selected CYP6P9a and CYP6P9b genes to expand the pyrethroid resistance front in the malaria vector Anopheles funestus in Africa. BMC Genomics 2014; 15:817.

32. Ibrahim SS, Riveron JM, Bibby J, et al. Allelic variation of cytochrome P450s drives resistance to bednet insecticides in a major malaria vector. PLoS Genet 2015; 11:e1005618.

33. Schmittgen TD, Livak KJ. Analyzing real-time PCR data by the comparative C(T) method. Nat Protoc. 2008;3(6):1101-8.

34. Tchouakui, M., Fossog, B. T., Ngannang, B. V., Njiokou, F., Djonabaye, D. \& Tchapga, W. Investigation of the influence of a glutathione S-transferase metabolic resistance to pyrethroids / DDT on mating competitiveness in males Anopheles funestus , African malaria vector (2019).

doi:10.12688/wellcomeopenres.15013.1

35. Djouaka R, Riveron JM, Yessoufou A, Tchigossou G, Akoton R, Irving H, et al. Multiple insecticide resistance in an infected population of the malaria vector Anopheles funestus in Benin. Parasit 
Vectors. 2016;9:453

36. Mulamba C, Riveron JM, Ibrahim SS, Irving H, Barnes KG, Mukwaya LG, et al. Widespread pyrethroid and DDT resistance in the major malaria vector Anopheles funestus in East Africa is driven by metabolic resistance mechanisms. PLoS ONE. 2014;9:e110058.

37. Mulamba C, Irving H, Riveron JM, Mukwaya LG, Birungi J, Wondji CS. Contrasting Plasmodium infection rates and insecticide susceptibility profiles between the sympatric sibling species Anopheles parensis and Anopheles funestus s.s.: a potential challenge for malaria vector control in Uganda. Parasit Vectors. 2014;7:71.

38. Hargreaves K, Koekemoer LL, Brooke BD, Hunt RH, Mthembu J, Coetzee M. Anopheles funestus resistant to pyrethroid insecticides in South Africa. Med Vet Entomol. 2000;14:181-9.

39. Riveron JM, Chiumia M, Menze BD, Barnes KG, Irving H, Ibrahim SS, et al. Rise of multiple insecticide resistance in Anopheles funestus in Malawi: a major concern for malaria vector control. Malar J. 2015;14:344.

40. Vezenegho SB, Chiphwanya J, Hunt RH, Coetzee M, Bass C, Koekemoer LL. Characterization of the Anopheles funestus group, including Anopheles funestus-like, from Northern Malawi. Trans R Soc Trop Med Hyg. 2013;107:753-62.

41. Wondji C, Frederic S, Petrarca V, Etang J, Santolamazza F, Della Torre A, et al. Species and populations of the Anopheles gambiae complex in Cameroon with special emphasis on chromosomal and molecular forms of Anopheles gambiae s.s. J Med Entomol. 2005;42:998-1005.

42. Kamdem C, Tene Fossog B, Simard F, Etouna J, Ndo C, Kengne P, Bousses P, et al. Anthropogenic habitat disturbance and ecological divergence between incipient species of the malaria mosquito Anopheles gambiae. PLoS ONE. 2012;7:e39453.

43. Simard F, Ayala D, Kamdem GC, Pombi M, Etouna J, Ose K, et al. Ecological niche partitioning between Anopheles gambiae molecular forms in Cameroon: the ecological side of speciation. BMC Ecol. 2009;9:17

44. Tchakounte A, Tchouakui M, Mu-Chun C, Tchapga W, Kopia E, Soh PT, et al. (2019) Exposure to the insecticide-treated bednet PermaNet 2.0 reduces the longevity of the wild African malaria vector Anopheles funestus but GSTe2-resistant mosquitoes live longer. PLoS ONE 14(3): e0213949. https://doi.org/10.1371/journal.pone.0213949

45. Riveron JM, Chiumia M, Menze BD, Barnes KG, Irving H, Ibrahim SS, et al. Rise of multiple insecticide resistance in Anopheles funestus in Malawi: a major concern for malaria vector control. Malar J. 2015;14:344.

46. Riveron JM, Huijben S, Tchapga W, Tchouakui M, Wondji MM, Tchoupo M, Irving H, Cuamba N, Maquina $\mathrm{M}$, Paaijmans $\mathrm{K}$, Wondji CS. Escalation of pyrethroid resistance in the malaria vector Anopheles funestus induces a loss of efficacy of PBO-based insecticide-treated nets in Mozambique. The Journal of infectious diseases. 2019.

47. Mulamba C, Irving H, Riveron JM, Mukwaya LG, Birungi J, Wondji CS. Contrasting Plasmodium infection rates and insecticide susceptibility profiles between the sympatric sibling species 
Anopheles parensis and Anopheles funestus s.s.: a potential challenge for malaria vector control in Uganda. Parasit Vectors. 2014;7:71.

48. 4 Riveron JM, Osae M, Egyir-Yawson A, Irving H, Ibrahim SS, Wondji CS. Multiple insecticide resistance in the major malaria vector Anopheles funestus in southern Ghana: implications for malaria control. Parasit Vectors. 2016;9(1):504.

49. Djouaka RJ, Atoyebi SM, Tchigossou GM, Riveron JM, Irving H, Akoton R, Kusimo MO, Bakare AA, Wondji CS. Evidence of a multiple insecticide resistance in the malaria vector Anopheles funestus in South West Nigeria. Malar J. 2016;15(1):565.

50. Wondji CS, Irving H, Morgan J, Lobo NF, Collins FH, Hunt RH, et al. Two duplicated P450 genes are associated with pyrethroid resistance in Anopheles funestus, a major malaria vector. Genome Res. 2009;19:452-9

51. Irving $\mathrm{H}$, Wondji $\mathrm{CS}$. Investigating knockdown resistance (kdr) mechanism against pyrethroids/DDT in the malaria vector Anopheles funestus across Africa. BMC Genet. 2017;18:76.

52. Riveron JM, Watsenga F, Irving H, Irish SR, Wondji CS. High Plasmodium infection rate and reduced bed net efficacy in multiple insecticide-resistant malaria vectors in Kinshasa, Democratic Republic of Congo. J Infect Dis. 2018;217:320-8.

53. Edi CV, Koudou BG, Jones CM, Weetman D, Ranson H. Multiple-insecticide resistance in Anopheles gambiae mosquitoes, Southern Cote d'Ivoir. Emerg Infect Dis. 2012;18:1508-11.

54. Nwane P, Etang J, Chouaïbou M, Toto JC, Mimpfoundi R, Simard F. Kdr based insecticide resistance in Anopheles gambiae s.s. populations in Cameroon: spread of the L1014F and L1014S mutations. BMC Res Notes. 2011;4:463.

55. Edi CV, Koudou BG, Jones CM, Weetman D, Ranson H. Multiple-insecticide resistance in Anopheles gambiae mosquitoes, Southern Cote d'Ivoir. Emerg Infect Dis. 2012;18:1508-11.

56. Weill M, Malcolm C, Chandre F, Mogensen K, Berthomieu A, Marquine M, et al. The unique mutation in ace-1 giving high insecticide resistance is easily detectable in mosquito vectors. Insect Mol Biol. 2004;13:1-7.

\section{Figures}




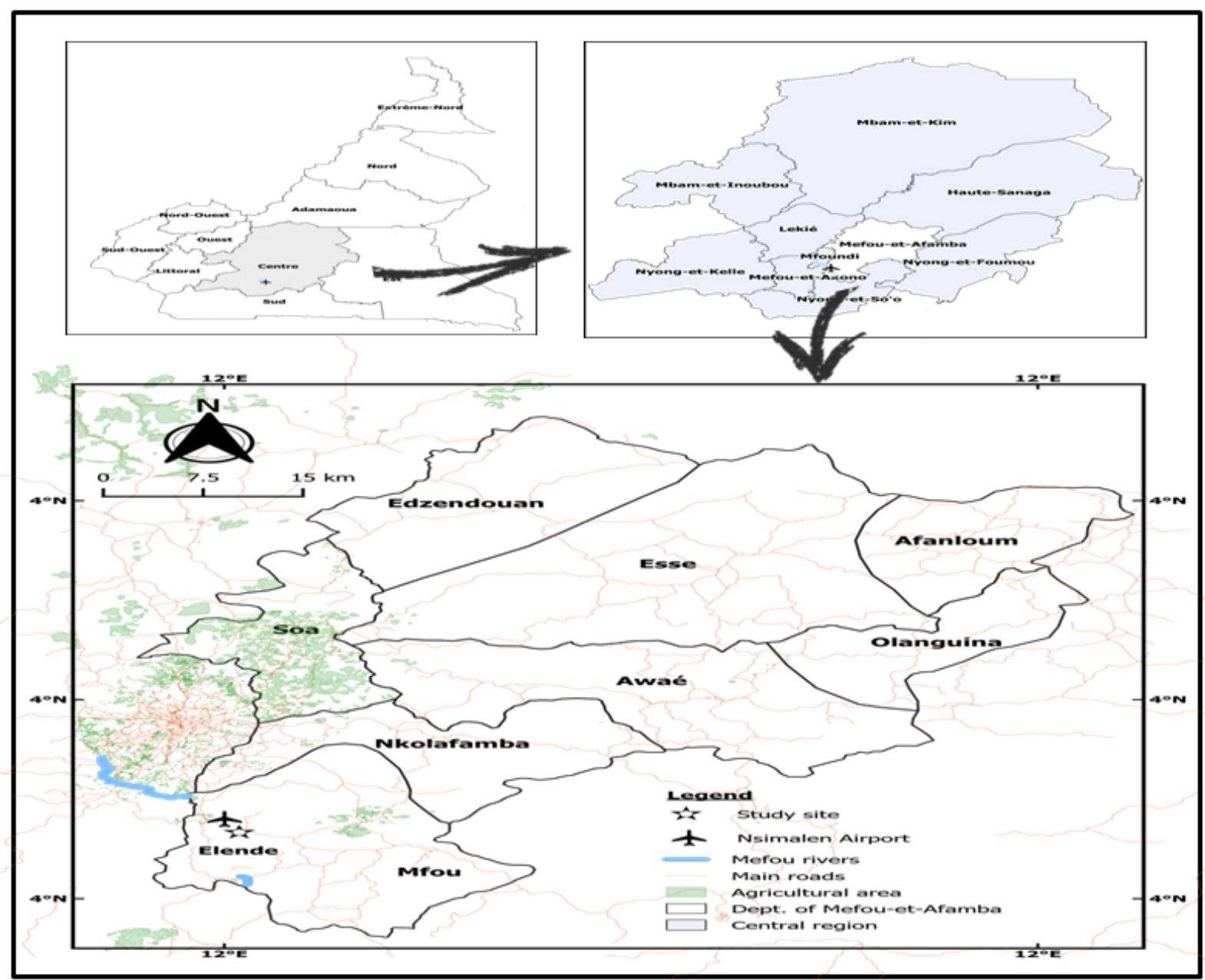

Figure 1

Map of Elende study area; showing its close proximity to the Nsimalen- International Airport of Yaoundé, capital city of Cameroon. 
a

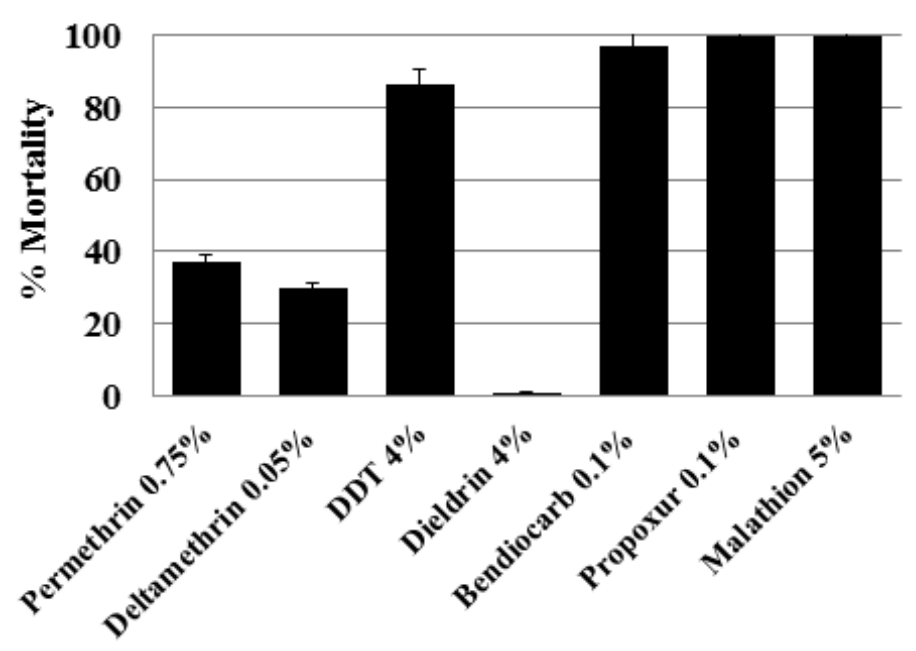

b

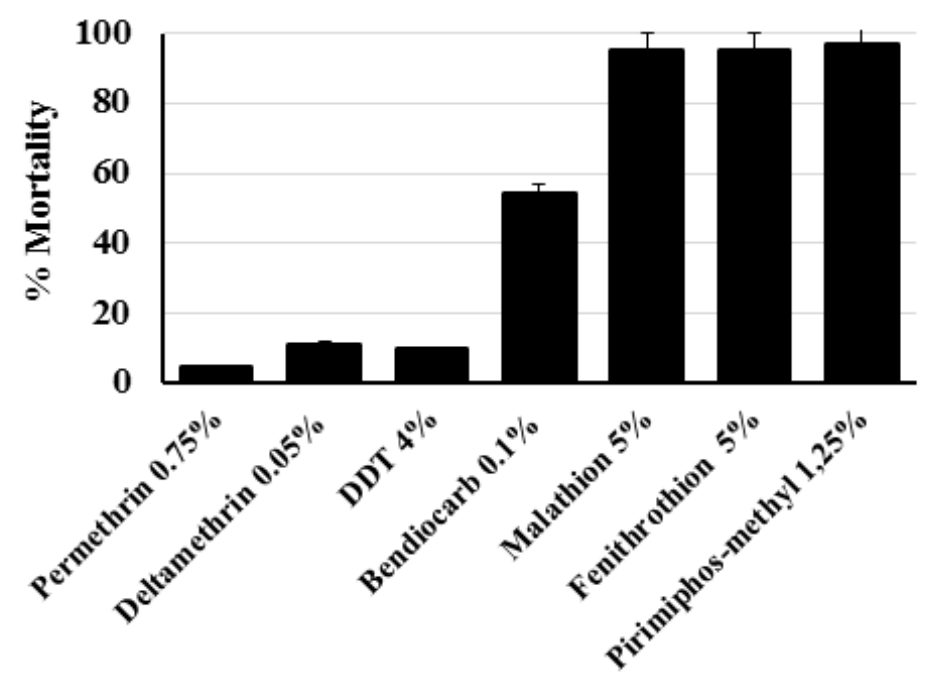

c

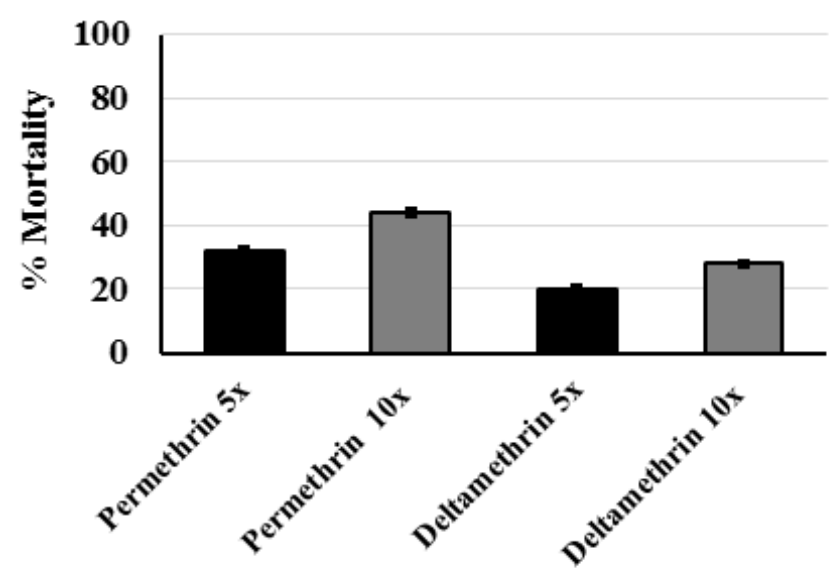

Figure 2

Results of WHO insecticides susceptibility test. a Susceptibility profile of female An. funestus s.s. (F1 progeny) from Elende following exposure to various public health insecticides. b Susceptibility profile of Elende female An. gambaie s.s. (F1 progeny). c Resistance intensity of An. gambiae s.s. (F1) on exposure to $5 x$ and $10 x$ permethrin and deltamethrin each. Error bars represent standard error of the mean. 


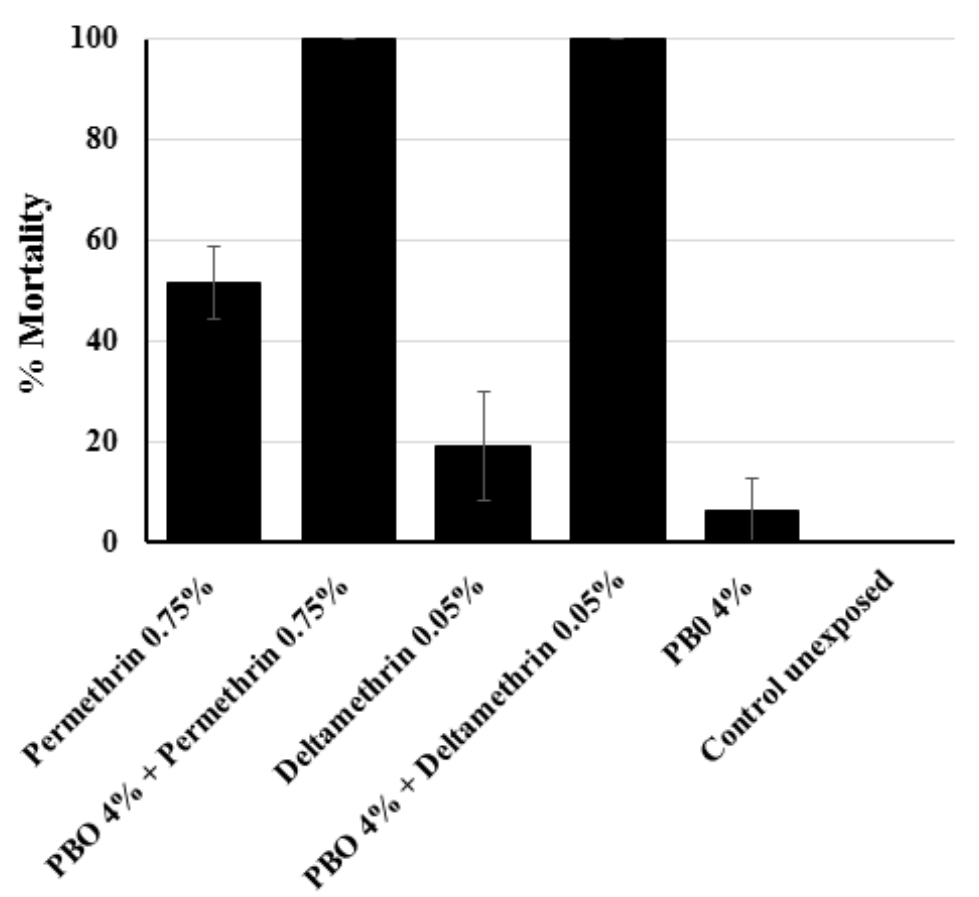

b

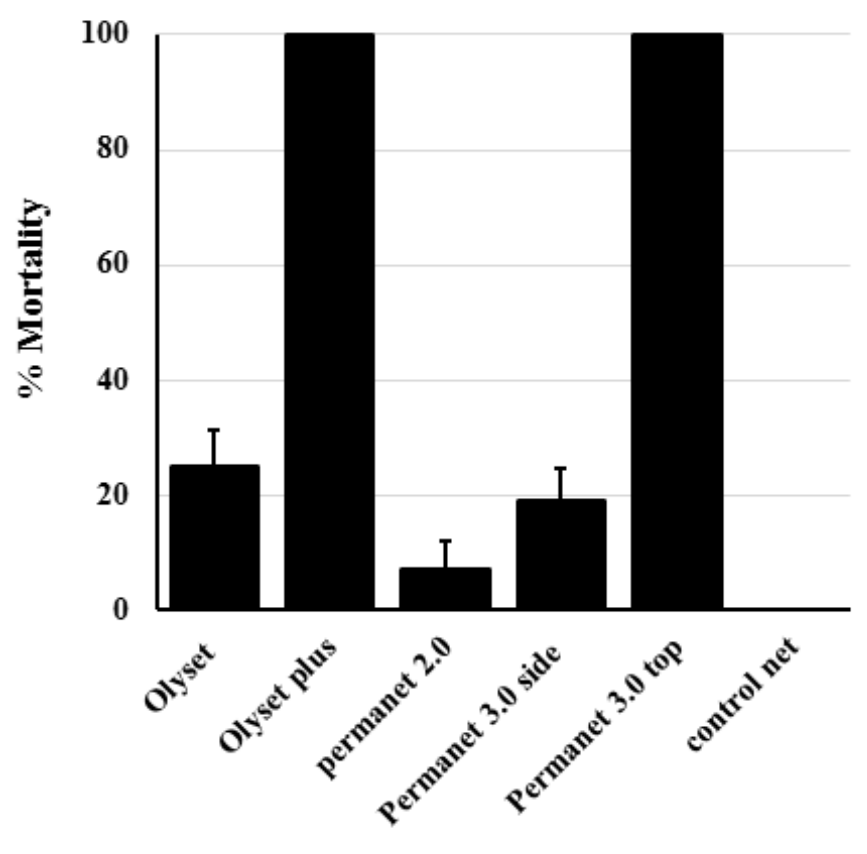

Figure 3

Susceptibility profile of An. funestus s.s. to synergist and cone assays from Elende. a Activities of PBO combined to permethrin and deltamethrin on An. funestus s.s. (F1 population). b Recorded mortalities following 3-min exposure by cone assay of An. funestus s.s. (F1 generation) from Elende to Olyset, Olyset Plus, PermaNet 2.0, PermaNet 3.0 (side) and PermaNet 3.0 (roof). Data are shown as mean \pm SEM. 
$\mathbf{a}$

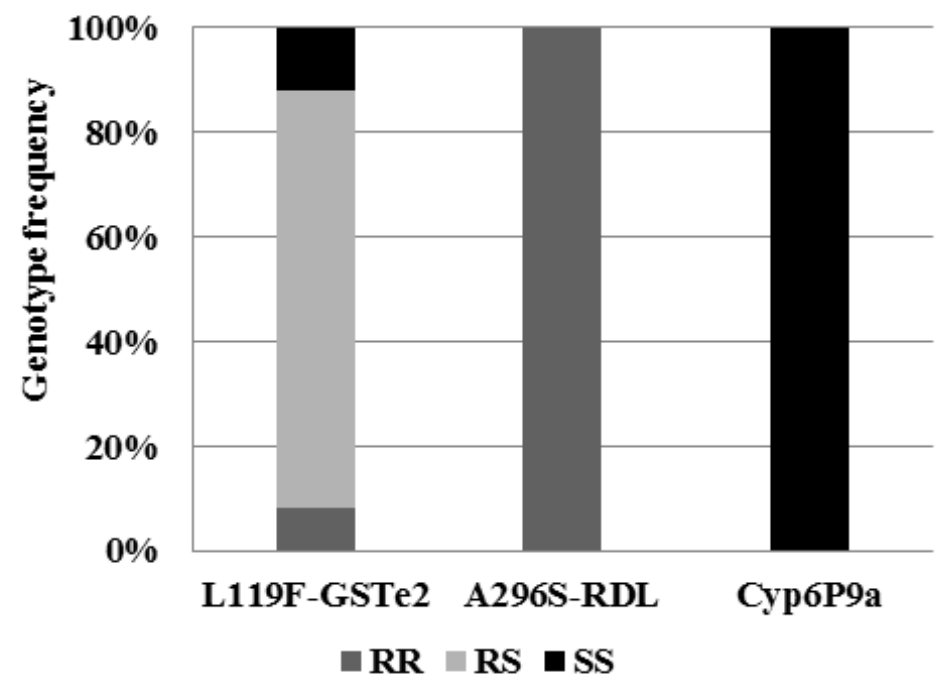

b

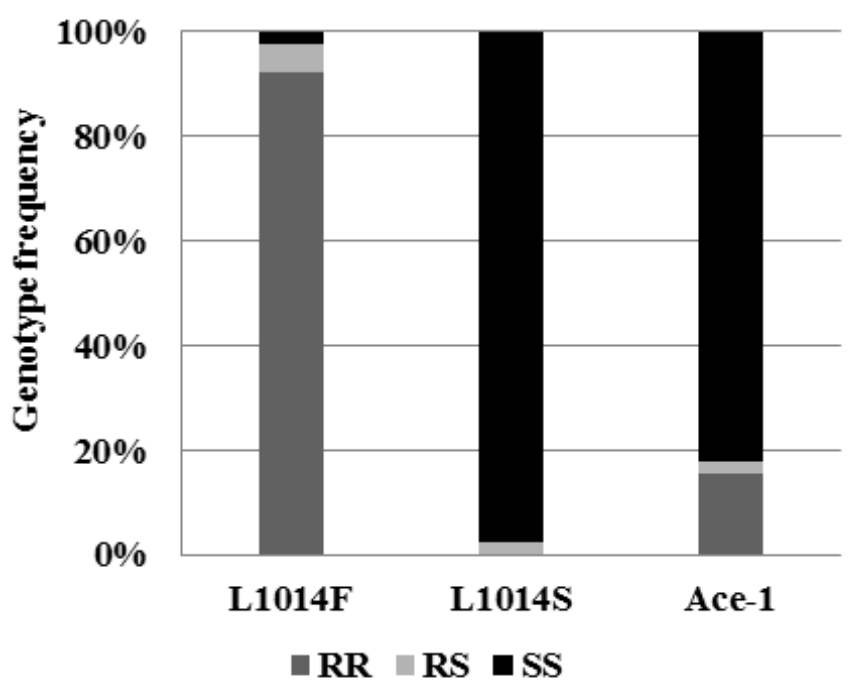

\section{Figure 4}

Temporal distribution of resistance markers in Elende. a) An. funestus s.s: Frequency of the L119F-GSTe2 conferring DDT resistance; A296S-RDL mutation conferring dieldrin resistance; Cyp6P9a related with pyrethroid resistance. b) An. gambiae s.s: Frequency of the L1014F conferring pyrethroids and DDT kdrW resistance; L1014S related with pyrethroids and DDT kdrE resistance; G119S ace-1 conferring carbamate and organophosphate resistance. Abbreviations: RR, homozygote for resistant allele; RS, heterozygote; SS, homozygote for susceptible allele. 


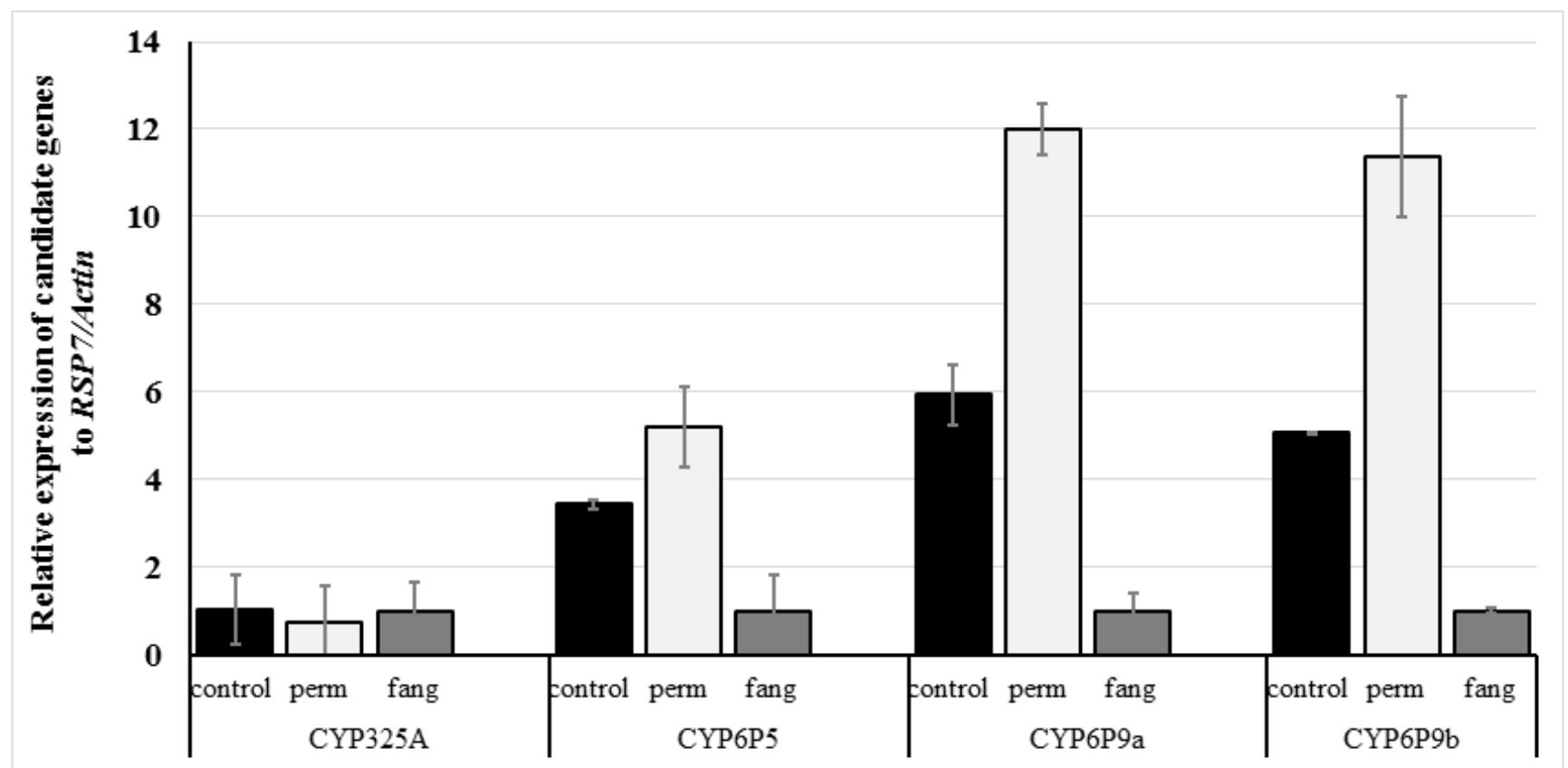

Figure 5

Differential expression by qRT-PCR of the major Cytochrome P450 genes (CYP325A, CYP6P5, CYP6P9a and CYP6P9b) in An. funestus s.s. in Elende compared with the susceptible A. funestus s.s. strain FANG. Error bars represent standard errors of the mean. 